\title{
Attenuating the visual suffix effect with color
}

\author{
ROBERT W. FRICK and ANTHONY DE ROSE \\ University of Washington, Seattle, Washington
}

\begin{abstract}
In previous studies using a short-duration visual presentation (200-340 msec), presentation of a different colored suffix did not attenuate the visual suffix effect. In Experiment 1, color attenuated the suffix effect for a longer duration visual presentation (approximately 3-4 sec) during which the subject engaged in articulatory suppression to prevent auditory recoding. Experiments 2 and 3 confirmed that color does not attenuate the suffix effect for the short-duration presentations. In Experiment 4, recall of a long-duration presentation was not improved when the last digit was a different color, suggesting that the different color of the suffix improves recall by allowing the suffix to be excluded from visual short-term memory. The attenuation by color is consistent with the hypothesis that preattentive grouping governs the entry of information into visual short-term memory.
\end{abstract}

Kahneman and Neisser (reported in Kahneman, 1973) presented digits visually for $200 \mathrm{msec}$ and asked subjects to recall the digits in order immediately after presentation. A zero was sometimes added to the end (far right) of this presentation. Subjects were told to ignore the zero, and a zero never appeared as one of the to-be-recalled digits; nonetheless, recall was impaired when the zero was present. This impairment can be called a visual suffix effect; it is analogous to the auditory suffix effect, an impairment in immediate ordered recall created by adding a to-be-ignored auditory item to the end of an auditory presentation (Dallet, 1964).

Immediate ordered recall of a short-duration visual presentation, such as that used by Kahneman and Neisser, appears to test the capacity of visual short-term memory (see Bongartz \& Scheerer, 1976, for a review). Visual short-term memory can also be tested with a longer duration visual presentation (Frick, 1985). In that paradigm, items are presented simultaneously for approximately $.5 \mathrm{sec}$ times the number of items. During the presentation, the subject engages in repetitive speech, called articulatory suppression, which prevents effective auditory recoding of the visual presentation (e.g., Murray, 1967). Articulatory suppression has been found not to impair performance on several tasks that presumably do not require auditory recoding (Klapp, Greim, \& Marshburn, 1981; Klapp, Marshburn, \& Lester, 1983; Richardson, 1984), suggesting that it does little more than disrupt auditory recoding. For both this long-duration presentation with articulatory suppression and the short-duration presenta-

Marlan Crosier, Terrence Winningham, Sheila Shatell, Meilene Chang, Barry Tregallas, Shawn Johns, and Claren Carrell assisted with testing subjects. Darla Broberg and Thomas Nelson criticized earlier drafts of this manuscript, and $\mathrm{G}$. Horton bequeathed funds for the equipment used in these experiments. Send reprint requests to Robert Frick, Department of Psychology NI-25, University of Washington, Seattle, WA 98195 . tion used by Kahneman and Neisser, the suffix impairs recall of the to-be-recalled digits approximately as much as if the suffix were another digit that had to be recalled (Frick \& De Rose, 1986).

Presenting additional repetitions of the suffix, as illustrated in the following configuration, can attenuate the visual suffix effect (Frick \& De Rose, in press; Kahneman, 1973; Kahneman \& Henik, 1977):

0
0
49852610
0
0

This attenuation shows the role of Gestalt principles of grouping in the visual suffix effect: With no additional zeros, a single-zero suffix is grouped with the to-berecalled digits by the Gestalt principles of proximity and good continuation. However, the additional zeros form a group with the zero suffix by the Gestalt principles of similarity (similar items tend to be grouped together) and good continuation (in this case, objects in a line are grouped together such that they continue in a line). When the zeros form one group, the to-be-recalled digits form another group that excludes the suffix, attenuating the suffix effect. This attenuation is not slight-a line of zeros creates little impairment in recall.

The attenuation of the suffix effect by Gestalt principles of grouping is one line of support for preattentive unit-formation (Neisser, 1967). Neisser suggested that the visual field is divided into objects, called "units," and that attention is directed toward one of these units. This is an object-based theory of attention, as opposed to a space-based theory (see Duncan, 1984, for a review). The visual stimulus at the retina is not already divided into units; rather, it must be divided during visual processing. This process of division is called "unit-formation" (Kahneman, 1973). If attention is to be directed toward objects, unit-formation must occur pre-attentively. The 
Gestalt principles of grouping describe the outcome of this unit-formation.

If the visual suffix effect and attenuations of the visual suffix effect are to be explained by the operations of preattentive unit-formation, then other methods of segregating the suffix by grouping should also attenuate the suffix effect. Presenting the suffix off-line from the to-berecalled items segregates the suffix by the Gestalt principle of good continuation, and it attenuates the suffix effect (Kahneman, 1973; Kahneman \& Henik, 1977). When the suffix is one color and the to-be-recalled digits are another color, the suffix would be segregated from the to-be-recalled items by color or the Gestalt principle of similarity. However, Kahneman and Henik (1977) found that color did not attenuate the suffix effect; that is, a suffix that was a different color than the to-be-recalled digits impaired recall as much as a suffix that was the same color as the to-be-recalled digits.

In an experiment by Routh and Walker (1975), a tobe-ignored prefix was placed in front of the to-be-recalled items in a 1-sec visual presentation. A prefix that was a different color than the to-be-recalled items impaired recall as much as a same-colored prefix. Routh and Walker noted that the grouping produced by the difference in color was "phenomenologically compelling," and claimed that the inability of color to attenuate the effect of the prefix was inconsistent with the hypothesis that unit-formation is involved in the visual suffix or prefix effects.

The phenomenological compellingness of grouping by color suggests that color should play at least some role in attenuating the suffix effect. Even if color by itself cannot attenuate the suffix effect, we hypothesized that color might interact with spatial location in attenuating the suffix effect. One experimental finding suggested the possibility of an interaction: When subjects are asked to recall items of a specific color from a brief multicolored visual presentation, they can recall proportionally more items than when asked to recall all of the items (von Wright, 1968). However, the improvement in recall is related to the extent to which the appropriately colored items are grouped spatially in a unit (Fryklund, 1975; Kahneman \& Henik, 1977).

Experiment 1 tested whether color would interact with spatial position to attenuate the visual suffix effect, using the paradigm with a long-duration visual presentation. Four different spatial configurations were used as suffixes, as shown here:

$\begin{array}{rrrr}\text { Sideways T } & \text { Sideways L } & \text { All on One Line } & \text { Single Suffix } \\ & 3 & & \\ 3 & 3 & & \\ 49852613 & 49852613 & 4985261333 & 49852613 \\ 3 & & & \end{array}$

In all four configurations, there was a 3 , which will be called the critical 3 , directly to the right of the to-berecalled items. In three of the configurations, there were two other $3 \mathrm{~s}$, which will be called extraneous $3 \mathrm{~s}$. The ex- traneous $3 \mathrm{~s}$ varied in position. In the first configuration, one extraneous 3 was above the critical 3 , and the other extraneous 3 was below, forming the shape of a sideways $T$. In this configuration, by the Gestalt principle of good continuation, the critical 3 was a member of the group of 3s. In the second configuration, both extraneous $3 \mathrm{~s}$ were directly above the critical 3 , forming the shape of a sideways L. In this configuration, by the Gestalt principle of good continuation, the critical 3 could be a member of either the to-be-recalled items or the group of $3 \mathrm{~s}$. In the third configuration, the extraneous $3 \mathrm{~s}$ followed the critical 3 on the same line. In this configuration, the Gestalt principle of good continuation did not segregate the critical 3 (or the extraneous $3 \mathrm{~s}$ ) from the to-be-recalled items. In the fourth configuration, there were no repetitions of the 3 .

There were four groups of subjects, corresponding to the four spatial configurations mentioned above. Each subject was tested for three different conditions. In one condition there was no suffix. In a second condition, the "same-color" condition, the critical 3 was the same color as the to-be-recalled items and the extraneous $3 \mathrm{~s}$ were a different color. By color, the same-color critical 3 was a member of the to-be-recalled items. In a third condition, the "different-color" condition, the critical 3 was a different color than the to-be-recalled items and the same color as the extraneous $3 \mathrm{~s}$. By color, the different-color critical 3 was not a member of the to-be-recalled items. In each suffix condition, the number of digits that the subject could recall in order immediately after presentation (capacity) was tested. The amount of attenuation produced by color was measured by the difference between the different-color condition and the same-color condition.

\section{EXPERIMENT 1}

\section{Method}

Subjects. Seventy-two students from introductory psychology classes at the University of Washington volunteered in order to earn extra credit toward their course grade.

Design. There were four groups of subjects. In all groups, a 3 (called the critical 3) was placed immediately after the to-be-recalled digits. The groups differed on the existence and placement of the extraneous $3 \mathrm{~s}$, as shown by the four configurations presented earlier. The extraneous $3 \mathrm{~s}$ were always a different color than the to-berecalled items. Testing of these four configurations was alternated.

For each configuration, three suffix conditions were tested, one with no suffix (i.e., the to-be-recalled items were not followed by any $3 \mathrm{~s}$ ), one in which the critical 3 was the same color as the tobe-recalled items, and one in which the critical 3 was a different color than the to-be-recalled items. Testing of these three conditions was blocked and counterbalanced for order.

Stimuli. The presentation of the stimuli was controlled by an Apple II+ computer with a Panasonic color monitor. The digit fonts were constructed for this experiment and presented using the highresolution screen of the Apple computer. The digits were approximately $9 \mathrm{~mm}$ high and $5 \mathrm{~mm}$ wide, with a $2-\mathrm{mm}$ space between each digit in the horizontal direction and between the critical $3 \mathrm{~s}$ in the vertical direction. The subject viewed these stimuli from a distance of approximately $.75 \mathrm{~m}$. Two colors, pink and blue, were 
used. The to-be-recalled digits were always one color, and this color was selected randomly before each trial.

The to-be-recalled digits were selected randomly with the following constraints: (1) The digit 3 was not included; (2) repetitions of a digit were separated by at least four intervening digits; and (3) adjacent digits never differed by 1 (e.g., 4 and 5 never occurred together).

Procedure. Subjects were tested individually. The procedure for the experiment was explained to each subject before beginning testing; in particular, the suffix was described and subjects were told not to recall the suffix. Each condition was again described before beginning that condition. Before testing, each subject read aloud a string of the 10 digits, to verify accurate perception of the digits.

Each trial began with a message indicating how many to-berecalled digits would be presented. This was followed by the message "ready" and then a message to begin articulatory suppression. At this time, the subject began repeating aloud " $A, B, C$, $D$ " at an even pace with no break between the $D$ and the $A$. The exact rate of the articulatory suppression was not controlled, but it was always fast enough to prevent intervals between letters in which subvocal rehearsal could occur. There was a pause in the presentation, then the digits were presented for approximately $560 \mathrm{msec}$ times the number of to-be-recalled digits.

When the presentation ended, the subject ceased articulatory suppression and attempted to recall the digits aloud in order from left to right. The experimenter recorded the subject's response, and signaled the result (correct, one wrong, or more than one wrong) to the computer. If there were any irregularities in the trial, such as the subject's halting of articulatory suppression during the presentation, the trial was repeated using a different string of digits.

Measuring capacity. Capacity was measured by a variation of the "up-down" method (e.g., Watkins \& Peynircioglu, 1983). In the up-down method, when the subject recalls a string correctly, the length of the string is incremented by one, and when the subject does not recall a string correctly, the length of the string is decremented by one. A subject's score is the average length of the string lengths that were tested. The string length that would have been used for the next trial after the final trial is included in this average; otherwise, the final trial would be irrelevant.

Several variations were made in this procedure. Two variations were attempts to increase reliability. First, if a subject made only one error in recall (forgetting or adding one digit, incorrectly recalling one digit, or reversing two adjacent digits), the length of the string was not changed. Second, even if a trial was correct, if a subject had not recalled at least $50 \%$ of the trials at the current string length, the number of digits in the string was not incremented. Similarly, the number of digits was not decremented when the subject had recalled more than $50 \%$ of the trials at the current length. A third variation bolstered the interval properties of the up-down method. The initial trials had a string length below the subject's capacity, so including them in the subject's score would have artificially lowered the score. The higher capacity was in relation to the starting level, the more the score would have been artificially lowered. To minimize the influence of the starting string length, the subject's score was the average of the string lengths beginning with the first trial that the subject did not recall correctly.

For each condition, there was 1 practice trial of five to-be-recalled digits and then 10 trials beginning with a trial of five to-be-recalled digits.

\section{Results}

The results are shown in Table 1. The same general pattern prevailed in all groups: Recall was best in the nosuffix condition, second best in the different-color condition, and poorest in the same-color condition. However, an overall analysis of variance yielded a group $\times$ suffix condition interaction $[F(6,136)=2.58, p<.05]$, suggesting that a separate analysis of each group was appropriate.
Table 1

Mean and Standard Error of the Mean for Capacity, Suffix Effect, and Attenuation of the Suffix Effect in Experiment 1

\begin{tabular}{lccc}
\hline & Capacity & $\begin{array}{c}\text { Suffix } \\
\text { Effect }\end{array}$ & $\begin{array}{c}\text { Attenuation } \\
\text { by Color }\end{array}$ \\
\hline $\begin{array}{l}\text { Single Suffix }(N=18) \\
\quad \text { No Suffix }\end{array}$ & 7.56 & & \\
$\quad$ Same Color & 6.78 & $.77 \pm .20^{*}$ & \\
$\quad$ Different Color & 7.34 & $.22 \pm .20$ & $.55 \pm 25^{*}$ \\
Same Line $(N=18)$ & & & \\
$\quad$ No Suffix & 7.96 & & \\
$\quad$ Same Color & 6.49 & $1.47 \pm .20^{*}$ & \\
$\quad$ Different Color & 7.67 & $.43 \pm .18^{*}$ & $1.04 \pm .16^{*}$ \\
Sideways L $(N=18)$ & & & \\
$\quad$ No Suffix & 7.66 & & \\
$\quad$ Same Color & 6.81 & $.84 \pm .25^{*}$ & \\
$\quad$ Different Color & 7.38 & $.27 \pm .20$ & $.57 \pm .19^{*}$ \\
Sideways T $(N=18)$ & & & \\
$\quad$ No Suffix & 7.95 & & \\
Same Color & 7.53 & $.41 \pm .24$ & \\
$\quad$ Different Color & 7.73 & $.22 \pm .19$ & $.20 \pm .19$ \\
\hline
\end{tabular}

${ }^{*} p<.05$.

When the $3 \mathrm{~s}$ were arranged to form a sideways $\mathrm{T}$, the overall difference between conditions was not statistically significant $[F(2,34)=1.99]$, and no pairwise comparisons were statistically significant. However, the group means were in the expected order, suggesting a small effect of color.

When the $3 \mathrm{~s}$ were arranged to form a sideways L, making group membership of the critical 3 ambiguous, color had an effect. Recall in the same-color condition was impaired 84 digits [compared with the no-suffix condition; $t(17)=3.34, p<.01]$, whereas the impairment in the different-color condition, .27 digits, was not statistically significant $[t(17)=1.40, p<.20]$. The two conditions differed by .57 digits $[t(17)=3.04, p<.01]$.

When the $3 s$ were arranged in one line continuous with the to-be-recalled digits, the color of the suffix had a large effect. The impairment in the same-color condition was 1.47 digits. This was statistically greater than 1 digit $[t(17)$ $=2.34, p<.05]$, which is to our knowledge the first report of a suffix effect reliably greater than 1 digit. Recall was also impaired .43 digits in the different-color condition $[t(17)=2.37, p<.05]$. The difference between the two suffix conditions was 1.04 digits $[t(17)=6.61, p<$ $.001]$.

Unexpectedly, color attenuated the suffix effect of a single 3 . When the 3 was a different color, the impairment in recall (.22 digits) was not statistically significant $[t(17)$ $=1.12 \mathrm{~J}$. When the 3 was the same color, there was an impairment of .77 digits $[t(17)=3.84, p<.01]$. The difference between the different-color condition and the same-color condition was .55 digits $[t(17)=2.40, p<$ $.05]$.

\section{Discussion}

The most important finding from Experiment 1 is that color can attenuate the effect of a single suffix. This result is predicted by the theory of unit-formation, but it had not been observed in previous experiments. 
Statistically, there was an interaction between color and spatial configuration in attenuating the suffix effect; in other words, the amount of attenuation by color depended upon the position of the extraneous $3 \mathrm{~s}$. However, this interaction can be attributed to ceiling effects: There was little suffix effect when the extraneous $3 \mathrm{~s}$ formed a sideways $T$, even when the critical 3 was the same color as the to-be-recalled digits. In this configuration, changing the color of the critical 3 did not have much of an opportunity to reduce the suffix effect. The other spatial configurations produced larger suffix effects, so in those configurations changing the color of the critical 3 had more of an opportunity to reduce the suffix effect. The results suggest that both spatial configuration and color can attenuate the suffix effect, and that the two methods of attenuating the suffix effect do not interact in any particularly interesting way.

One point not specifically about color should be made. In previous investigations of the attenuation of the visual suffix effect by the addition of extraneous items, good continuation was confounded with the principle of similarity. In the three different configurations of extraneous $3 \mathrm{~s}$ in Experiment 1, the amount of segregation by good continuation was varied, whereas the amount of segregation by similarity remained constant. The effect of good continuation was strong, as can be seen by comparing recall when the extraneous $3 \mathrm{~s}$ formed a sideways $\mathrm{T}$ with recall when the extraneous $3 \mathrm{~s}$ were on the same line. The influence of the principle of similarity can be estimated by comparing the group with the extraneous $3 \mathrm{~s}$ on the same line (in which similarity was present to segregate the suffix) with the single-suffix group (in which similarity was not present). The extra $3 \mathrm{~s}$ on the same line did not reduce the suffix effect, suggesting that, at least in the conditions of this experiment, the principle of similarity did not segregate the suffix from the to-be-recalled items. Routh and Walker (1975) similarly found that repeating a prefix three times on the same line did not reduce the effect of a visual prefix. Grouping by similarity does not seem to be phenomenologically compelling, so the failure of similarity to attenuate the suffix effect is not evidence against the role of pre-attentive unit-formation in attenuating the suffix effect.

We should also note, as a methodological point, that when we used a 0 suffix instead of a 3 , color did not attenuate the suffix effect. In a pilot study of 12 subjects, using different fonts and a different measure of digit capacity, the same-colored suffix impaired recall .39 digits $[t(11)=2.83, p<.05]$, the different-colored suffix impaired recall .33 digits $[t(11)=4.34, p<.01]$, and the difference between the two suffixes was nonsignificant $[t(11)=.33]$. The attenuation by color using a 3 suffix and the lack of attenuation by color using a 0 suffix was so surprising that we suspected a statistical fluke. Therefore, 18 subjects were tested using the procedure for the single-suffix group of Experiment 1, except for using a 0 as the suffix instead of a 3 (and using 3 in the set of possible to-be-recalled digits instead of 0 ). Again, there was no attenuation by color: The same-colored suffix im- paired recall .55 digits $[t(17)=4.12, p<.001]$, the different-colored suffix impaired recall .42 digits $[t(17)$ $=3.10, p<.01]$, and the difference between the two suffixes, .13 digits, was not statistically significant $[t(17)$ $=.66]$.

In two other experiments we have performed using the long-duration visual presentation, the 0 did not create as large a suffix effect as did the 3 . We hypothesize that this might be related to the 0's role as a place-saver in the Arabic numeral system. However, we have no explanation for why color would not attenuate the suffix effect of the 0 .

\section{EXPERIMENT 2}

The finding that color attenuates the effect of a single suffix is inconsistent with previous findings (Kahneman, 1973; Kahneman \& Henik, 1977). There were many procedural differences between Experiment 1 and previous experiments. However, the obvious difference is that Experiment 1 used a long-duration presentation, whereas previous experiments had used short-duration presentations (in which the digits were presented for only $200 \mathrm{msec}$ ). To verify that the critical difference between Experiment 1 and previous experiments was the duration of the presentation, Experiment 2 tested the attenuation of the single-suffix effect by color for long-duration versus short-duration visual presentations.

In Experiment 1, the color of the to-be-recalled digits was unpredictable; that is, the color was not known until the digits were presented. The unpredictability of the color presumably had little effect in the long-duration presentation, but it might make attenuation of the suffix more difficult for the short-duration visual presentation: Humphreys (1981) found that differences in color allowed subjects to attend to one stimulus and ignore another in a short-duration visual presentation, but only when subjects knew beforehand the color of the stimuli. When the color was unpredictable, color had no effect. Furthermore, in a pilot study of the short-duration presentation using unpredictable color, we found no attenuation of the suffix effect by color. To maximize the probability that color would attenuate the suffix effect in the short-duration visual presentation of Experiment 2, color was made predictable by having the to-be-recalled digits be the same color across all of the trials by a subject.

\section{Method}

There were 48 subjects. Half of the subjects were tested with a long-duration visual presentation with articulatory suppression, as in Experiment 1. The other half of the subjects were tested with a short-duration visual presentation. The order of testing was alternated.

The short-duration visual presentation differed from the longduration visual presentation in the following aspects: The to-berecalled digits were presented for approximately $340 \mathrm{msec}$. This duration seemed short enough to prevent auditory recoding and long enough to prevent perceptual difficulties. Articulatory suppression was not used in this condition, because the presentation presumably was fast enough to prevent auditory recoding and because previous studies had not used articulatory suppression. Before the presen- 
tation of the digits, a dot flashed on and off twice in the center of the location where the to-be-recalled digits would be presented. The dot was flashed rhythmically in time with the presentation, so it cued both when and where the digits would be presented.

The color of the to-be-recalled digits was the same for all of the trials by a subject. The two colors, pink and blue, were varied orthogonally with which type of presentation was tested and the order of testing conditions.

The methodology otherwise followed the single-suffix group of Experiment 1.

\section{Results and Discussion}

The results are shown in Table 2 . The critical question is whether the amount of attenuation by color in the longduration presentation was greater than the amount of attenuation by color in the short-duration presentation. The appropriate analysis is a $2 \times 2$ ANOVA, with one factor being the duration of presentation and the other factor being the color of the suffix. (The amount of attenuation is measured by the difference between the two suffix conditions, so the condition with no suffix was ignored in this analysis.) There was a main effect of duration of presentation $[F(1,46)=36.46, p<.001]$, resulting from the superior recall of the long-duration presentation, and there was a main effect of color of the suffix $[F(1,46)=$ $7.92, p<.01]$. The interaction between these two factors was statistically significant $[F(1,44)=7.34, p<$ $.01]$, suggesting that the extent to which color attenuated the suffix effect depended upon whether the long-duration presentation or the short-duration presentation was being tested. Therefore, a separate analysis of these two types of presentation is appropriate.

The results from the long-duration presentation were similar to those in Experiment 1: The same-colored suffix impaired recall .82 digits $[t(23)=5.61, p<.001]$, the impairment created by the different-colored suffix $(.31$ digits) approached statistical significance in this experiment $[t(23)=1.79, p<.10]$, and the difference between the two suffixes (.50 digits) was again statistically significant $[t(23)=2.99, p<.01]$. Therefore, color attenuated the suffix effect in the long-duration visual presentation.

In the short-duration presentation, the same-colored suffix impaired recall .70 digits $[t(23)=7.03, p<.001]$, and the different-colored suffix impaired recall .69 digits $[t(23)=6.65, p<.001]$. The difference between the

Table 2

Mean and Standard Error of the Mean for Capacity, Sufrix Effect, and Attenuation by Color in Experiment 2

\begin{tabular}{llll}
\multicolumn{4}{c}{ Effect, and Attenuation by Color in Experiment 2} \\
\hline & Capacity & $\begin{array}{l}\text { Suffix } \\
\text { Effect }\end{array}$ & $\begin{array}{c}\text { Attenuation } \\
\text { by Color }\end{array}$ \\
\hline $\begin{array}{l}\text { Short Presentation }(N=24) \\
\text { No Suffix }\end{array}$ & 6.38 & & \\
Same Color & 5.67 & $.70 \pm .10^{*}$ & \\
Different Color & 5.68 & $.69 \pm .10^{*}$ & $.01 \pm .07$ \\
Long Presentation $(N=24)$ & & & \\
No Suffix & 7.45 & & \\
Same Color & 6.64 & $.82 \pm .15^{*}$ & \\
Different Color & 7.14 & $.31 \pm .18$ & $.50 \pm .17^{*}$ \\
\hline${ }^{*} p<.05$. & & & \\
\end{tabular}

Table 3

Mean and Standard Error of the Mean for Capacity, Suffix Effect, and Attenuation by Color in Experiment 3

\begin{tabular}{llll}
\hline & Capacity & $\begin{array}{l}\text { Suffix } \\
\text { Effect }\end{array}$ & $\begin{array}{c}\text { Attenuation } \\
\text { by Color }\end{array}$ \\
\hline $\begin{array}{l}\text { Short Presentation }(N=18) \\
\quad \text { No Suffix }\end{array}$ & 6.21 & & \\
$\quad$ Same Color & 5.45 & $.76 \pm .10^{*}$ & \\
$\quad$ Different Color & 5.49 & $.71 \pm .15^{*}$ & $.05 \pm .11$ \\
Long Presentation $(N=18)$ & & & \\
$\quad$ No Suffix & 7.72 & & \\
Same Color & 6.97 & $.75 \pm .21^{*}$ & \\
Different Color & 7.50 & $.22 \pm .20$ & $.53 \pm .13^{*}$ \\
\hline
\end{tabular}

${ }^{*} p<.05$.

two suffix conditions, .01 digits, was not statistically significant $[t(23)=.14]$. Therefore, color did not attenuate the suffix effect in the short-duration presentation.

\section{EXPERIMENT 3}

In Experiment 2, the obvious difference between the short-duration presentation and the long-duration presentation was simply the duration. However, the two presentations also differed in the presence versus absence of articulatory suppression, with articulatory suppression used only in the long-duration presentation. It seemed unlikely that the difference between the two conditions resulted from the articulatory suppression. As already noted, articulatory suppression usually has little effect other than to prevent auditory recoding. Nonetheless, to empirically rule out the possibility that the difference between the two conditions was produced by articulatory suppression, Experiment 3 replicated Experiment 2, except that articulatory suppression was used with both the short- and longduration presentations.

\section{Method}

Thirty-six subjects were tested. The methodology followed Experiment 2 except for the presence of articulatory suppression. As in the long-duration presentation, in the short-duration presentation the subjects received a message indicating that they should begin articulatory suppression. They continued articulatory suppression until the presentation was ended.

\section{Results and Discussion}

The results, shown in Table 3, replicated those of Experiment 2. In particular, the interaction between color of the suffix and duration of the presentation was statistically significant $[F(1,34)=8.08, p<.01]$. Color attenuated the suffix effect in the long-duration presentation $[t(17)=4.04, p<.001]$ but not in the short-duration presentation.

It seems that the increased duration of the presentation, not the presence of articulatory suppression, allowed color to attenuate the suffix effect.

\section{EXPERIMENT 4}

The evidence so far demonstrates that a suffix of a different color improves recall (in the long-duration presentation). 
Why does the different color improve recall? We argued elsewhere (Frick \& De Rose, 1986) that (1) one unit is selected to enter visual short-term memory, and (2) units are defined by the same process of pre-attentive unitformation that defines units for attention. The to-be-recalled digits form a unit by the principles of proximity and good continuation. The single suffix is grouped with the to-berecalled digits, so it is included in visual short-term memory. When the suffix enters visual short-term memory, it uses some of the available capacity, thereby impairing recall. However, when extraneous items form a new unit that includes the suffix, the to-be-recalled digits form a unit excluding the suffix; this unit can be selected to enter visual short-term memory, avoiding the suffix effect.

Given this explanation, there are two ways that a different color of suffix might improve recall. First, color might influence unit-formation, such that the different-colored suffix can be excluded from visual short-term memory. However, another alternative does not involve excluding the different colored suffix. It is possible that recall of a set of digits is improved when the last digit is a different color than the other digits. For example, a differentcolored last digit might create less interference while residing with the other digits in visual short-term memory, or a different-colored last digit might be easier to differentiate from the other digits during retrieval from short-term memory. Suppose immediate recall is improved when the last digit is a different color. Then even if both suffixes enter visual short-term memory, recall would be better when there was a different-colored suffix than when there was a same-colored suffix.

To test whether having a different-colored last item improves recall of the long-duration presentation, recall without any suffix was tested in Experiment 4 . In one condition all of the digits were the same color, and in the second condition the last digit was a different color than the other digits.

\section{Method}

Eighteen subjects were tested. There were two conditions, one in which the digits were all the same color, and one in which the last digit was a different color than the other digits. For both conditions, the long-duration visual presentation with articulatory suppression was used. The digits were selected from the set 1-9. There was no suffix. The methodology otherwise followed the single-suffix group in Experiment 1.

\section{Results and Discussion}

The average digit capacity when the last digit was a different color was 6.70 , and the average when the last digit was the same color was 6.97 . The difference between the two conditions ( .27 digits) approached statistical significance $[t(17)=1.96, p<.10]$. However, the direction of the difference was opposite to that expected if, in fact, a different-colored last digit improves recall.

This result provides no support for the hypothesis that the different color of the suffix improves recall because of its memorial properties. Instead, the different color ap- parently facilitates excluding the suffix from visual shortterm memory.

\section{GENERAL DISCUSSION}

To summarize, in Experiment 1 the suffix effect for a long-duration visual presentation was attenuated when the suffix was a different color than the to-be-recalled digits. This attenuation occurred for spatial configurations of variously placed extraneous $3 \mathrm{~s}$, but it also occurred for a single 3 suffix. Experiments 2 and 3 confirmed that there was no attenuation by color for a short-duration presentation. Experiment 4 showed that recall with no suffix was not improved when the last digit was a different color than the other digits.

Phenomenologically, color groups the stimuli such that the suffix is not grouped with the to-be-recalled stimuli. Therefore, a different-colored suffix would be expected to attenuate the suffix effect by allowing the suffix to be excluded from short-term memory. In the long-duration presentation, the different-colored suffix did attenuate the suffix effect, apparently by allowing the suffix to be excluded from visual short-term memory. An alternative hypothesis, that both the same-colored suffix and the different-colored suffix enter visual short-term memory but that the different-colored suffix creates less impairment once in visual short-term memory, was not supported by Experiment 4.

The puzzling aspect of these data is that color attenuated the suffix effect in the long-duration presentation and not in the short-duration presentation. It is not true that all attenuations require time to develop. Attenuations occur in the short-duration presentation when extraneous repetitions of the suffix are added to the presentation and when the suffix is presented off-line (Kahneman, 1973; Kahneman \& Henik, 1977). These successful attenuations are based upon spatial information instead of color, and they are based upon the principle of good continuation, whereas the attenuation by color presumably is based upon the principle of similarity.

It seems that color was not a strong method of grouping in the $200-340 \mathrm{msec}$ of the short-duration visual presentation. Color presumably is a powerful factor for grouping adjacent points of the visual field. However, the to-be-recalled digits were separated by spaces, and there is no reason why color should be a strong factor for grouping disconnected objects. Nonetheless, color was strong enough to attenuate the suffix effect in the long-duration presentation. Thus, grouping by color is weak in the shortduration presentation but strong in the long-duration presentation.

If all grouping increased over time, the same factors that were stronger than color in the short-duration presentation would still be stronger than color in the longduration presentation, and color still would not attenuate the suffix effect. Instead, the influence of color seems to increase over time relative to the other factors. 
One possibility is that color's influence over grouping automatically increases with time. Three considerations weigh against this possibility. First, arguing that color's influence occurs after $340 \mathrm{msec}$ posits a very slow perceptual process, by perceptual standards. Second, it is not clear what would be the ecological value of having the results of unit-formation automatically change over time. Third, consider the results from Experiment 1 when the suffix was the same-color as the to-be-recalled items and the extraneous $3 \mathrm{~s}$ were positioned in the shape of a sideways T. Color would have tended to group the critical 3 with the to-be-recalled items, yet the suffix effect was not much larger than when the critical 3 was a different color. This suggests that if the influence of color automatically increases over time, it never achieves the strength of good continuation.

Another possibility is based upon the suggestion by Wertheimer (1923/1938) that unit-formation can be influenced by attentive (i.e., conscious) processes. Consider the following configuration:

$$
\begin{array}{lllll}
0 & 0 & 0 & 0 & 0 \\
0 & 0 & 0 & 0 & 0 \\
0 & 0 & 0 & 0 & 0 \\
0 & 0 & 0 & 0 & 0 \\
0 & 0 & 0 & 0 & 0
\end{array}
$$

By the principle of proximity, this configuration tends to be viewed as five rows rather than five columns. However, with a little effort, five columns can be seen. This control over how the configuration is grouped suggests that attentive processes can influence unit-formation. It seems possible that color is not a strong method of grouping, but that with conscious attention it can be used to segregate the suffix from the to-be-recalled digits. In the short-duration presentation, perhaps there was not enough time for these attentive processes to occur.

If subjects had complete control over unit-formation, they could have avoided the suffix effect in the longduration presentation. However, as Wertheimer noted, there seem to be limits to the control over unit-formation. In the just-presented configuration, complex organizations of dots are difficult to see. For example, one diagonal row of dots can be constructed, but seeing all the dots in diagonal rows is difficult.

In conclusion, color can attenuate the suffix effect for a long-duration visual presentation. This attenuation is consistent with the hypothesis that visual short-term memory contains one unit defined according to Gestalt principles of grouping. The lack of attenuation by color in the short-duration visual presentation suggests that the results of unit-formation might change over time, perhaps as a result of attentive processes.

\section{REFERENCES}

Bongartz, W., \& Scheerer, E. (1976). Two visual stores and two processing operations in tachistoscopic partial report. Quarterly Journal of Experimental Psychology, 28, 203-219.

DALLET, K. M. (1964). Effects of a redundant prefix on immediate recall. Journal of Experimental Psychology, 67, 296-298.

DUNCAN, J. (1984). Selective attention and the organization of visual information. Journal of Experimental Psychology: General, 113, 501-517.

FrICK, R. W. (1985). Testing visual short-term memory: Simultaneous versus sequential presentations. Memory \& Cognition, 13, 346-356.

FrICK, R. W., \& DE Rose, A. (1986). The suffix effect and pre-attentive unit-formation in visual short-term memory. Canadian Journal of Psychology, 40, 97-108.

FrYKLUND, I. (1975). Effects of cued-set spatial arrangement and targetbackground similarity in the partial-report paradigm. Perception \& Psychophysics, 17, 375-386.

HUMPHREYS, G. W. (1981). Flexibility of attention between stimulus dimensions. Perception \& Psychophysics, 30, 291-302.

Kahneman, D. (1973). Attention and effort. Englewood Cliffs, NJ: Prentice-Hall.

Kahneman, D., \& HeniK, A. (1977). Effects of visual grouping on immediate recall and selective attention. In S. Dornic (Ed.), Attention and performance VI (pp. 307-332). Hillsdale, NJ: Erlbaum.

Klapp, S. T., Grem, D. M., \& Marshburn, E. A. (1981). Buffer storage of programmed articulation and articulatory loop: Two names for the same mechanism or two distinct components of short-term memory? In J. Long \& A. Baddeley (Eds.), Attention and performance $I X$ (pp. 459-472). Hillsdale, NJ: Erlbaum.

KLAPP, S. T., Marshburn, E. A., \& Lester, P. T. (1983). Short-term memory does not involve the "working memory" of information processing: The demise of a common assumption. Journal of Experimental Psychology: General, 112, 240-264.

MURRAY, D. J. (1967). The role of speech responses in short-term memory. Canadian Journal of Psychology, 21, 263-276.

NeISSER, U. (1967). Cognitive psychology. New York: AppletonCentury-Crofts.

RICHARDSON, J. T. E. (1984). Developing the theory of working memory. Memory \& Cognition, 12, 71-83.

RouTH, D. A., \& WALKER, D. J. (1975). "Next-to-nothings" and nothingness: A study of attention, attenuation and the stimulus prefix effect. Quarterly Journal of Experimental Psychology, 27, 393-403.

VON WRIGHT, J. M. (1968). Selection in visual immediate memory. Quarterly Joumal of Experimental Psychology, 20, 62-68.

Watkins, M. J, \& Peynircioglu, Z. F. (1983). Interaction between presentation modality and recall order in memory span. American Journal of Psychology, 96, 315-322.

WERTHEIMER, M. (1938). Laws of organization in perceptual forms. In W. D. Ellis (Ed. and Trans.), A source book of Gestalt psychology (pp. 71-88). New York: Harcourt, Brace. (Original work published in 1923)

(Manuscript received July 12, 1985; revision accepted for publication March 18, 1986.) 